\title{
Immigrant-native differences in caries-related knowledge, attitude, and oral health behaviors: a cross-sectional study in Taiwan
}

\author{
Chih-Chang Chen ${ }^{1,2}$, Shang-Jyh Chiou ${ }^{3}$, Chun-Chan Ting ${ }^{4}$, Ying-Chun Lin ${ }^{4}$, Chih-Cheng Hsu ${ }^{5}$, Fu-Li Chen ${ }^{6}$, \\ Chien-Hung Lee ${ }^{7}$, Ted Chen ${ }^{8}$, Chin-Shun Chang ${ }^{9}$, Ya-Ying Lin ${ }^{10}$ and Hsiao-Ling Huang ${ }^{1 *}$
}

\begin{abstract}
Background: With the growing number of transnational marriages in Taiwan, oral health disparities have become a public health issue. This study assessed immigrant-native differences in oral health behaviors of urban mothers and their children.

Methods: We used the baseline data of an oral health promotion program to examine the immigrant-native differences in caries-related knowledge, attitude, and oral health behaviors. A cross-sectional study was conducted to collect data from mothers in urban area, Taiwan. A total of 150 immigrant and 440 native mothers completed the self-report questionnaires. Logistic regression models analyzed the racial differences in oral health behaviors.

Results: Approximately 37\% of immigrant mothers used dental floss, $25 \%$ used fluoride toothpaste, and only $13.5 \%$ of them regularly visited a dentist. Less that $40 \%$ of immigrant mothers brush their children's teeth before aged one year, $45 \%$ replaced child's toothbrush within 3 months, and only half of the mothers regularly took their child to the dentist. Immigrant mothers had lower level of caries-related knowledge and attitudes than native mothers $(p<.001)$. Compared to native group, the immigrant mothers were less likely to use of dental floss ([Adjusted odds ratio $(a \mathrm{OR})=0.35]$, fluoride toothpaste $(\mathrm{aOR}=0.29)$, visit a dentist in the past 2 years $(\mathrm{aOR}=0.26)$, and take their children to regular dental check-up ( $\mathrm{aOR}=0.38$ ); whereas, they were more likely to not consume sweeten beverages $(\mathrm{aOR}=3.13)$.

Conclusions: The level of caries-related knowledge, attitudes and oral health behaviors were found lower in immigrant mothers than native ones. The findings suggested cross-cultural caries prevention programs aimed at reducing immigrant-native disparities in child oral health care must be developed for these immigrant minorities.
\end{abstract}

Keywords: Attitudes, Behavior, Dental caries, Immigrants, Health care

\section{Background}

Dental caries is one of the most common preventable childhood diseases, and the most common chronic disease for people worldwide. Dental caries affects general health and the quality of life in preschool children [1]. Pain caused by severe caries can cause poor chewing and affected the quantity and variety of food eaten. Also, it can make eating of high sucrose diet more likely that can compromise intake of other nutrients [1,2]. By 2011, the overall caries prevalence of Taiwanese preschoolers

\footnotetext{
* Correspondence: hhuang@kmu.edu.tw

'Department of Oral Hygiene, College of Dental Medicine, Kaohsiung Medical University, 100 Shih-Chuan 1st Road, Kaohsiung 80708, Taiwan Full list of author information is available at the end of the article
}

was $79.3 \%$, significantly higher than in European countries and the United States, and higher than the World Health Organization (WHO) 2020 global goals for oral health: "More than $90 \%$ of preschool children free of dental caries" [3].

Since 2000, the number of immigrant women from Southeast Asia has increased rapidly in Taiwan. The majority of immigrant women are Vietnamese (64.7\%) and Indonesian (20.5\%), followed by Thais, Filipinos, and Cambodians. These women are colloquially called "foreign brides" or "alien brides" because their marriages were arranged by marriage brokers. The aggregate number of Southeast Asian wives in Taiwan was estimated at more than 466,000 , or approximately one-third of Taiwanese

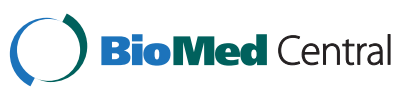


marriages. One in 12 children were born of a foreign spouse by 2011 [4].

With the growing number of transnational marriages in Taiwan, health disparities have become a vital public health issue, especially in maternal and child health. Oral health inequalities exist between immigrants and nonimmigrants. Previous studies conducted in Europe and the United States highlighted the worsening dental status of immigrant children [5-7]. Among immigrant children aged 4 to 6 years in Taiwan, the caries index was significant higher than in native children (6.05 vs. 3.88) [8]. The risk factors for preschool children with caries experience were found positively associated with parents in lower educational levels, scant parental attention to the child's tooth-brushing habits, poor parental brushing habits, and higher frequency of sugar intake among parents $[5,9,10]$, with parents playing an important role in preschool children's caries.

Immigrant mothers have difficulty accessing the health care system because of language barriers, cultural conflicts, social and interpersonal isolation, and a lack of support systems [11]. Literature showed that unemployment, inequality and poverty is a root cause to poor health status, especially in developing countries. The social dimension of globalization encompasses security, culture and identity, inclusion or exclusion and the cohesiveness of families and communities that can impact on the health status of individual, family and society. It can also lead to deteriorating nutritional intake and inaccessibility to medical services [12,13]. Immigrant women in Taiwan were living in households with low family incomes and educations, in contrast to the native group, which has gradually led to inferior medical care for these women and their children [14]. Numerous studies reported that health insurance can increase dental care use and that is a contributing factor in the decision to seek health care services $[15,16]$. The Taiwanese National Health Insurance (NHI) program provides universal and comprehensive health insurance with low co-payments for dental care. Dental care insurance has $100 \%$ coverage excluding non-health problem procedures including orthodontics, prosthetic and dental implant but scaling [17]. Nevertheless, previous study [8] showed that immigrant children had lower numbers of dental restoration treatments than did native children, causing further oral health inequalities. The Taiwanese government has recently begun to pay more attention to the health care for these immigrants and provides several gratis services; however, those above services do not involve some essential oral health services. In addition, the services in the Health Care Service Project (HCSP) by the Department of Health only targets at premarital or prenatal women while the HCSP does not directly provide oral health services for preschool children, and ignores the oral health status of preschool children in new immigrant groups.

The 5-year Lay Health Advisor Approach to Promote Oral Health Program (LHA-POHP), promoting the oral health of new immigrant children, was first implemented in the Kaohsiung area in 2011. The LHA's strategies are feasible and effective for promoting health care, especially among disparate immigrant populations $[18,19]$. We therefore used the baseline data of the LHA Program to explain the immigrant-native differences in caries-related knowledge, attitudes, and oral health behaviors.

\section{Methods}

Data were obtained from the baseline data of the LHA Program. The LHA Program was originally constructed based on the PRECEDE-PROCEED framework [20] and LHA strategy to promote oral health in the children of women in transnational marriages in Taiwan. A community-based survey was conducted to collect baseline data in 2011. The self-reported questionnaire was used to assess the caries-related knowledge, attitudes, and behaviors among the immigrant and native mothers.

\section{Study design}

The data of immigrants were collected from 20 communities selected from a list of 87 urban communities in Kaohsiung, which were selected based on the high proportion of Vietnamese and Indonesian mothers who received care from the Kaohsiung San-Min District Health Sector. The 20 communities were selected based on the availability of large number of immigrant mothers, support of village head, suitable facility for survey and oral examination.

We used a systematic random sampling method to select native children from kindergarten schools, of which 9 schools were randomly selected from a list of kindergartens located in San-Ming District provided by the Education Bureau of Kaohsiung City. All of the schools agreed to participate in the study, and all the children aged 4 to 6 years and their mothers were invited to participate.

\section{Participants}

A sample size calculation was established by comparing proportions between the values found in native and immigrant children, using an $80 \%$ power (beta) and 5\% significance (alpha) for calculation. The sample size was estimated at 422 natives and 89 immigrants. A total of 150 immigrant and 440 native mothers were administered questionnaires. The response rate for the native and immigrant mothers was $96.3 \%$ and $78.9 \%$, respectively. The average ages of the mothers were 29.3 and 36.2 years for immigrant and native mothers, respectively. 


\section{Instrument}

\section{Questionnaire development}

The self-administered questionnaire was modified from an established and validated questionnaire used in a recent study [9]. The questionnaire was reviewed by a panel of experts, teachers, and the children's mothers to assess its content and validity. To ensure that the content was understood by our participants, the questionnaire was piloted to 50 mothers of kindergarten children. Based on the results of the pilot testing, items were revised to enhance clarification and appropriateness.

The questionnaire included 63 items with close-ended response formats, such as dichotomous, ordinal, and multilevel response choices, to assess oral health behavior and its relevant variables. The questionnaire was first developed in Chinese, and then translated into Vietnamese and Indonesian by 2 bilingual experts. To ensure translation accuracy, both the Vietnamese and Indonesian versions were translated back into Chinese and then verified for accuracy by 2 senior researchers. We delivered questionnaires to all participating mothers under examination conditions overseen by trained LHA program research staff.

\section{Variables}

\section{Participant demographics}

Basic demographic information consisted of maternal age, education level, employment status, and monthly household income.

\section{Knowledge of the caries-related scale}

The following 9-item scale statements, which we developed, were used to assess the mothers' knowledge regarding caries and dental care services: "We have two sets of teeth in a lifetime"; "Incisors are rectangular and used for cutting food"; "Canines are triangular and used for tearing food apart"; "When newborns or young children have no teeth, we do not need to help them clean their mouths"; "Although parents kiss their children without brushing their teeth, this will not cause children to have dental caries"; "The Bureau of National Health Insurance (BNHI) provides children with fluoride varnish twice a year"; "We should pay attention to the cartoon images on a toothbrush when choosing a toothbrush"; "Dental plaque is caused by bacteria on the tooth surface"; and "The four factors of dental caries are teeth, food, bacteria, and time." Possible responses included true, false, or unknown with possible scores ranging from 0 to 9; higher scores indicated a better degree of knowledge regarding caries and oral health. A 0.72 on the Kuder-Richardson reliability test was deemed acceptable.

\section{Attitudinal scales}

Eighteen questions regarding attitude, including attitudes toward oral hygiene (9 items), attitudes toward diet (4 items), and parental indulgence attitudes (5 items), were based the research by Skeie et al. [9]. The questionnaire was measured on a 5-point Likert scale with ratings from 1 (strongly disagree) to 5 (strongly agree). Cumulative scores were summed for each attitudinal scale, with higher scores reflecting more positive attitudes toward oral hygiene, diet, and child rearing. Cronbach's alpha coefficients for the 3 scales ranged from 0.63 to 0.84 .

\section{Maternal oral health behaviors}

Mothers' oral health behaviors consisted of mother's oral health behaviors (13 items) and their behaviors toward oral health of children (10 items). Participants responded to questions such as "How many times do you brush your teeth each day?" in the domain of the mothers' oral health behaviors and "How old was your child the first time you assisted him or her in brushing his or her teeth?" in the domain of mothers behavior toward oral health of children. The items of the oral health behavior of mothers and their children were described elsewhere [8].

\section{Statistical analysis}

This study explored the relationship among the variables using STATA version 10.0. The chi-square test was used to compare the new immigrant and native groups regarding the demographic distribution. A two-sample $t$ test compared the new immigrant and native mothers for caries-related knowledge, attitudes toward oral hygiene, attitudes toward diet, and parental indulgence attitudes; The chi-square test was used to compare differences in the oral health behavior of both groups. A $p$ value $<.05$ indicated a statistically significant difference between the 2 groups. In order to assess the unadjusted and adjusted association, both univariate and multivariate regression models were estimated. Only the maternal behaviors that were found to be significant associated with racial difference in the univariate regression were put into the multiple regression models. Adjusted odds ratios and 95\% confidence intervals were reported for the multivariate analysis.

\section{Ethical considerations}

This study was approved by the IRB of KMU Hospital, and we obtained letters of consent from all participants.

\section{Results}

The demographic distribution of immigrant and native mothers

Table 1 shows the demographic information of the native and immigrant groups. For immigrant mothers, the 
Table 1 Demographic information of immigrant and native mothers

\begin{tabular}{|c|c|c|c|c|}
\hline \multirow[t]{2}{*}{ Variables } & \multicolumn{2}{|c|}{ Immigrant $(n=150)$} & \multicolumn{2}{|c|}{ Native $(n=440)$} \\
\hline & $\mathrm{N}$ & $\%$ & $\mathrm{~N}$ & $\%$ \\
\hline \multicolumn{5}{|l|}{ Age } \\
\hline$<30$ & 96 & 67.61 & 36 & 8.65 \\
\hline$>=30$ & 46 & 32.39 & 380 & 91.35 \\
\hline \multicolumn{5}{|l|}{ Educational level } \\
\hline Less than high school & 106 & 71.62 & 14 & 3.31 \\
\hline High school & 38 & 25.68 & 153 & 36.17 \\
\hline College or higher & 4 & 2.70 & 256 & 60.52 \\
\hline \multicolumn{5}{|l|}{ Occupation } \\
\hline Full-time & 43 & 29.05 & 239 & 56.10 \\
\hline Part-time & 17 & 11.49 & 36 & 8.45 \\
\hline Unemployed & 88 & 59.46 & 151 & 35.45 \\
\hline \multicolumn{5}{|l|}{ Household income } \\
\hline$<$ NTD 40,000 & 80 & 58.82 & 114 & 26.89 \\
\hline NTD 40,000-59,999 & 44 & 32.35 & 103 & 24.29 \\
\hline >NTD 59,999 & 12 & 8.82 & 207 & 48.82 \\
\hline \multicolumn{5}{|l|}{ Marital status } \\
\hline Married, living together & 142 & 95.95 & 352 & 81.11 \\
\hline Separately & 4 & 2.70 & 46 & 10.60 \\
\hline Divorce or others & 2 & 1.35 & 36 & 8.29 \\
\hline
\end{tabular}

majority was aged under 30 years (67.61\%), had no high school education (97.30\%), and was unemployed (59.46\%). Furthermore, $58.8 \%$ of the immigrant mothers had a household income under NTD\$40,000 (\$USD 1,360) per month, whereas $73.1 \%$ of native mothers had household incomes over $\$ 40,000$ per month.

\section{Comparison of the caries-related knowledge and attitudes} in immigrant and native mothers

The comparisons of average scores of caries-related knowledge and attitudes are shown in Table 2. The mean scores of knowledge, attitudes toward oral hygiene, attitudes toward diet, and parental indulgence attitudes between the immigrant and native mother groups showed significant differences $(p<.001)$.

\section{Oral health behaviors of mothers and their children}

Table 3 shows the distribution of the oral health behaviors of mothers and their children between the immigrant and native groups. For immigrant mothers, 68.28\% reported that they replaced their toothbrush within 3 months, $13.1 \%$ replaced it in over 3 months, and $18.62 \%$ replaced when it broke. Only $37.24 \%$ of immigrant mothers reported that they flossed their teeth, compared to $74.49 \%$ of native mothers. Approximately $50 \%$ of immigrant mothers reported that they are uncertain about using fluoride toothpaste, and $62.73 \%$ of native mothers chose fluoride toothpaste.

The following 2 questions regarding maternal diet behaviors were significantly different for the 2 groups: "How many times per week do you consume sweeten beverages?" $31.25 \%$ of immigrant stated 3 or more times per week compared to $42.01 \%$ in native mothers; for "How many times per week do you consume sweets?" $22.22 \%$ of immigrant mothers responded to 3 times or more per week; however, $32.18 \%$ of native mothers answered 3 times or more per week. For mother's dental visit behaviors, both groups did not visit the dentist regularly, with rates of $86.49 \%$ and $76.59 \%$ in immigrant and native mothers, respectively $(p=.010)$. Fewer immigrant mothers (71.92\%) visited a dentist in the past 2 year, compared to native mothers $(89.20 \%)(p=.001)$.

The 3 following questions regarding maternal behaviors toward cleaning teeth of children showed significant immigrant-native differences: "How old was your child the first time you assisted him/her in brushing his/her teeth?"; $62.33 \%$ of immigrant mothers responded with 1 year of age or older, but $61.73 \%$ of native mothers responded with under 1 year of age; for "How often do you replace your child's toothbrush?" $64.38 \%$ of immigrant mothers stated within 3 months, but $73.97 \%$ of native mothers replaced it within 3 months; only $30.30 \%$ of immigrant mother responded with 3 minutes or more to "How many minutes does your child spend brushing his/her teeth?"

Table 2 Comparison of the mothers' caries-related knowledge, attitudes toward oral hygiene, attitudes toward diet and parental indulgence attitudes in the immigrant and native group

\begin{tabular}{|c|c|c|c|c|c|c|c|c|c|}
\hline \multirow[t]{2}{*}{ Variables } & \multicolumn{4}{|c|}{ Immigrant } & \multicolumn{4}{|c|}{ Native } & \multirow[t]{2}{*}{$p$-value } \\
\hline & $\mathrm{N}$ & Mean & SD & $95 \% \mathrm{Cl}$ & $\mathbf{N}$ & Mean & SD & $95 \% \mathrm{Cl}$ & \\
\hline Knowledge & 137 & 5.15 & 2.08 & $4.80-5.51$ & 432 & 7.69 & 1.41 & $7.56-7.83$ & $<0.001$ \\
\hline Attitudes toward oral hygiene & 133 & 34.85 & 4.62 & $34.06-35.64$ & 436 & 37.55 & 4.86 & $37.10-38.01$ & $<0.001$ \\
\hline Attitudes toward diet & 140 & 15.09 & 2.90 & $14.61-15.58$ & 435 & 16.28 & 2.81 & $16.01-16.54$ & $<0.001$ \\
\hline Parental indulgence attitudes & 137 & 16.28 & 3.16 & $15.75-16.81$ & 435 & 18.11 & 3.07 & $17.82-18.40$ & $<0.001$ \\
\hline
\end{tabular}

a-test statistics. 
Table 3 Distribution of oral health behaviors among immigrant and native mothers and their children

\begin{tabular}{llllll}
\hline Items & \multicolumn{2}{l}{ Immigrant } & & Native & $p$-value \\
\cline { 2 - 3 } & $\mathrm{N}$ & $\%$ & $\mathrm{~N}$ & $\%$ \\
\hline
\end{tabular}

\section{Maternal oral health behaviors}

\section{Cleaning teeth}

How many times do you brush your teeth every day?

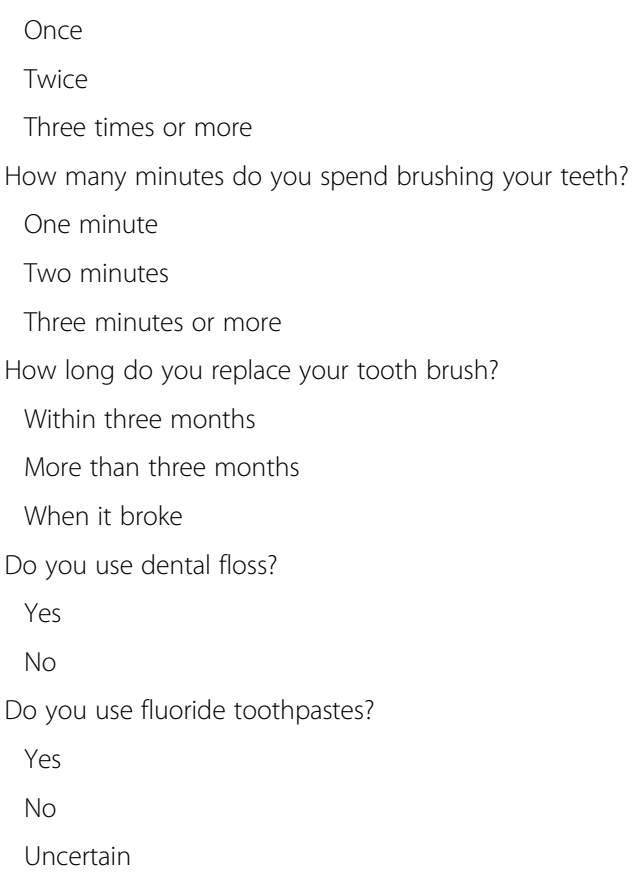

\section{Diet habit}

How many times per week do you consume sweeten beverages?

Once

Twice

Three times or more

How many times per week do you consume sweets?

Once

Twice

Three times or more

\section{Dental visit}

Do you regularly visit a dentist?

Yes, every six months

No

Have you visited the dentist in the past two years?

Yes

No

$\begin{array}{cccc}10 & 6.80 & 27 & 6.18 \\ 105 & 71.43 & 314 & 71.85 \\ 32 & 21.77 & 96 & 21.97 \\ & & & \\ 35 & 24.31 & 84 & 19.22 \\ 53 & 36.81 & 210 & 48.05 \\ 56 & 38.89 & 143 & 32.72 \\ & & & \\ 99 & 68.28 & 325 & 74.54 \\ 19 & 13.10 & 85 & 19.50 \\ 27 & 18.62 & 26 & 5.96 \\ & & & \\ 54 & 37.24 & 327 & 74.49 \\ 91 & 62.76 & 112 & 25.51 \\ & & & \\ 35 & 24.31 & 276 & 62.73 \\ 36 & 25.00 & 131 & 29.77 \\ 73 & 50.69 & 33 & 7.50\end{array}$

0.964

0.061

$<0.001$

$<0.001$

$<0.001$

0.015

$<0.001$

$\begin{array}{llll}95 & 65.97 & 200 & 45.98\end{array}$

$\begin{array}{llll}17 & 11.81 & 95 & 21.84\end{array}$

$\begin{array}{llll}32 & 22.22 & 140 & 32.18\end{array}$

Maternal behaviors toward oral health of their children

Cleaning teeth of children

How old was your child the first time you assisted him/her in brushing his/her teeth? 
Table 3 Distribution of oral health behaviors among immigrant and native mothers and their children (Continued)

\begin{tabular}{|c|c|c|c|c|c|}
\hline How often do you replace your child's toothbrush? & & & & & $<0.001$ \\
\hline Within three months & 94 & 64.38 & 324 & 73.97 & \\
\hline More than three months & 22 & 15.07 & 95 & 21.69 & \\
\hline When it broke & 30 & 20.55 & 19 & 4.34 & \\
\hline Do you use a feeding bottle before your child goes to sleep? & & & & & 0.150 \\
\hline Yes & 46 & 31.51 & 111 & 25.40 & \\
\hline No & 100 & 68.49 & 326 & 74.60 & \\
\hline Do you direct your child to brush his/her teeth? & & & & & 0.739 \\
\hline Yes & 145 & 97.97 & 427 & 97.49 & \\
\hline No & 3 & 2.03 & 11 & 2.51 & \\
\hline How many minutes does your child spend brushing his/her teeth? & & & & & $<0.001$ \\
\hline One minute & 53 & 40.15 & 189 & 47.13 & \\
\hline Two minutes & 39 & 29.55 & 165 & 41.15 & \\
\hline Three minutes or more & 40 & 30.30 & 47 & 11.72 & \\
\hline \multicolumn{6}{|l|}{ Diet habit of children } \\
\hline How many times per week do your children consume sweets? & & & & & 0.013 \\
\hline Once & 41 & 27.89 & 77 & 17.78 & \\
\hline Twice & 26 & 17.69 & 112 & 25.87 & \\
\hline Three times or more & 80 & 54.42 & 244 & 56.35 & \\
\hline How many times per week do your children consume sweeten beverages? & & & & & 0.054 \\
\hline Once & 62 & 42.76 & 145 & 33.03 & \\
\hline Twice & 30 & 20.69 & 128 & 29.16 & \\
\hline Three times or more & 53 & 36.55 & 166 & 37.81 & \\
\hline \multicolumn{6}{|l|}{ Dental visit of children } \\
\hline Do you regularly take your child to the dentist? & & & & & $<0.001$ \\
\hline Yes, every six months & 80 & 53.69 & 379 & 86.53 & \\
\hline No & 69 & 46.31 & 59 & 13.74 & \\
\hline Have you taken your child to the dentist in the past two years? & & & & & $<0.001$ \\
\hline Yes & 104 & 71.72 & 378 & 86.50 & \\
\hline No & 41 & 28.28 & 59 & 13.50 & \\
\hline
\end{tabular}

Regarding dietary habits of children, $54.42 \%$ of immigrant mothers reported 3 times or more a week to "How many times per week do your children consume sweets?" compared to $56.35 \%$ of native mothers $(p=.013)$. For dental visit of children, only $53.69 \%$ of immigrant mothers brought their children for regular dental check-ups, but $86.53 \%$ of native mothers brought theirs. Fewer immigrant mothers $(71.72 \%)$ brought their children to visit a dentist in the past 2 years, compared to native mothers (86.50\%). Both questions were significantly different, as shown in Table $3(p<.001)$.

\section{Racial difference related to oral health behaviors}

Table 4 and Table 5 shows multivariate logistic regression analysis of racial difference related to maternal oral health behaviors and maternal behaviors toward oral health of their children. After adjusting for potential covariates, the immigrant mothers were less likely to use of dental floss [Adjusted odds ratio $(\mathrm{aOR})=0.35 ; 95 \% \mathrm{CI}=0.17-0.75$ ], use of fluoride toothpaste $(\mathrm{aOR}=0.29 ; 95 \% \mathrm{CI}=0.13-0.64)$ and dental visit in the past 2 years $(\mathrm{aOR}=0.26 ; 95 \%$ $\mathrm{CI}=0.10-0.65)$; whereas they were more likely to not consuming sweeten beverages $(\mathrm{aOR}=3.13$; $95 \% \mathrm{CI}=1.47$ 6.67). Mothers who have higher level of caries-related knowledge were more likely to use of dental floss $(\mathrm{aOR}=1.14 ; 95 \% \mathrm{CI}=1.00-1.31)$, fluoride toothpaste $(\mathrm{aOR}=1.18 ; 95 \% \mathrm{CI}=1.03-1.34)$ and dental visit in the past 2 years $(\mathrm{aOR}=1.19 ; 95 \% \mathrm{CI}=1.02-1.40)$. Mothers who have positive attitude toward oral health were more likely to have regular dental check-ups every 6 months $(\mathrm{aOR}=1.03 ; 95 \% \mathrm{CI}=1.01-1.06)$. 
Table 4 Multivariate logistic regression analysis of racial difference related to maternal oral health behaviors

\begin{tabular}{|c|c|c|c|c|c|c|c|c|c|c|}
\hline \multirow[t]{2}{*}{ Characteristics } & \multicolumn{2}{|c|}{ Model A } & \multicolumn{2}{|c|}{ Model B } & \multicolumn{2}{|c|}{ Model C } & \multicolumn{2}{|c|}{ Model D } & \multicolumn{2}{|c|}{ Model E } \\
\hline & $\mathrm{aOR}$ & $(95 \% \mathrm{Cl})$ & $\mathrm{aOR}$ & $(95 \% \mathrm{Cl})$ & $\mathrm{aOR}$ & $(95 \% \mathrm{Cl})$ & $\mathrm{aOR}$ & $(95 \% \mathrm{Cl})$ & $\mathrm{aOR}$ & $(95 \% \mathrm{Cl})$ \\
\hline \multicolumn{11}{|l|}{ Race } \\
\hline Native & 1 & & 1 & & 1 & & 1 & & 1 & \\
\hline Immigrant & 0.35 & $(0.17-0.75)$ & 0.29 & $(0.13-0.64)$ & 3.13 & $(1.47-6.67)$ & 1.24 & $(0.42-3.69)$ & 0.26 & $(0.10-0.65)$ \\
\hline \multicolumn{11}{|l|}{ Age } \\
\hline$>=30$ & 1 & & 1 & & 1 & & 1 & & 1 & \\
\hline$<30$ & 1.08 & $(0.60-1.95)$ & 0.66 & $(0.40-1.19)$ & 0.45 & $(0.26-0.81)$ & 0.88 & $(0.41-1.88)$ & 2.34 & $(1.08-5.04)$ \\
\hline \multicolumn{11}{|l|}{ Educational level } \\
\hline College or higher & 1 & & 1 & & 1 & & 1 & & 1 & \\
\hline High school & 1.23 & $(0.73-2.08)$ & 0.85 & $(0.53-1.36)$ & 1.20 & $(0.76-1.88)$ & 0.38 & $(0.21-0.71)$ & 0.96 & $(0.47-1.99)$ \\
\hline Less than high school & 0.67 & $(0.29-2.08)$ & 0.97 & $(0.40-2.35)$ & 0.85 & $(0.37-1.92)$ & 0.70 & $(0.22-2.21)$ & 1.18 & $(0.39-3.55)$ \\
\hline \multicolumn{11}{|l|}{ Household income } \\
\hline >NTD 59,999 & 1 & & 1 & & 1 & & 1 & & 1 & \\
\hline NTD 40,000-59,999 & 1.52 & $(0.87-2.67)$ & 1.33 & $(0.80-2.23)$ & 1.07 & $(0.66-1.73)$ & 0.87 & $(0.49-1.53)$ & 1.04 & $(0.49-2.19)$ \\
\hline$<$ NTD 40,000 & 0.89 & $(0.52-1.50)$ & 1.23 & $(0.74-2.05)$ & 1.09 & $(0.67-1.76)$ & 0.69 & $(0.37-1.30)$ & 1.03 & $(0.50-2.13)$ \\
\hline Knowledge & 1.14 & $(1.00-1.31)$ & 1.18 & $(1.03-1.34)$ & 0.97 & $(0.86-1.10)$ & 1.18 & $(0.98-1.42)$ & 1.19 & $(1.02-1.40)$ \\
\hline Attitudes & 0.98 & $(0.96-1.01)$ & 1.02 & $(0.99-1.05)$ & 1.01 & $(0.99-1.03)$ & 1.03 & $(1.00-1.06)$ & 1.00 & $(0.97-1.04)$ \\
\hline
\end{tabular}

aOR was adjusted for covariates in the table.

Model A: Maternal dental floss use (Yes vs. No).

Model B: Maternal fluoride toothpastes use (Yes vs. No).

Model C: Maternal consumption of sweeten beverages per week (Once or less vs. Twice or more).

Model D: Maternal regular dental check-up (Yes vs. No).

Model E: Visited a dentist in the past two years (Yes vs. No).

Compare to native mothers, the immigrant mothers were less likely to take their children to regular dental check-up ( $\mathrm{aOR}=0.38 ; 95 \% \mathrm{CI}=0.17-0.83)$. Those mothers who have high level of knowledge score were more likely to assist child in brushing before the age of one $(\mathrm{aOR}=1.23 ; 95 \% \mathrm{CI}=1.08-1.40)$. Mothers who have positive attitudes toward oral health were more likely to replace child's toothbrush within three months $(\mathrm{aOR}=1.04$; 95\% $\mathrm{CI}=1.01-1.07)$ and take child regular dental check-ups every 6 months $(\mathrm{aOR}=1.05 ; 95 \% \mathrm{CI}=1.02-1.08)$.

\section{Discussion}

Our study is the first to identify a correlation between immigrant-native disparities and oral health behaviors in urban mothers and their children in Taiwan. According to our results, immigrant-native differences in knowledge, attitude and behaviors toward oral health of mothers and their children were observed. Our findings also confirmed that racial difference was related to oral health behavior of mothers and their children.

The findings of this study showed significantly lower level of caries-related knowledge in immigrant mothers which indicate a higher demand for immigrant mothers for oral health knowledge. Moreover, our study shows that immigrant mothers have more negative attitudes toward oral hygiene, diet, and parental indulgence compared to native mothers. Attitudes are derived from targeted beliefs; each belief and behavior are connected to a specific result, leading to the implementation of production [21].

In this study, the frequency of immigrant mothers' oral health behaviors was lower than for native mothers. Less than $40 \%$ of immigrant mothers assisted their children in tooth brushing before the age of one. Skeie [9] found that the rate of helping children younger than 1 year brush their teeth for immigrant mothers was lower than for native mothers. Fewer regular dental checkups in immigrant mothers and their children were also observed in our study. Cultural differences in dental attendance and self-care practices of children and their parents, such as higher percentage of sweet consumption and lower percentage of dental health practice among immigrant children have been reported in previous studies $[22,23]$. The study showed that at age seven, $53 \%$ of native Danish and $84 \%$ of Albanian children were founded infected with dental caries. The mean caries infection was more serious among Albanian children than native Danish children (13.8 vs. 3.5). Socio-behavioral factors are responsible in making dental caries prevalence and severity among these two groups of children. Despite dental visits for children aged 6 years and under being free of charge under Taiwanese health insurance coverage, our study found that few immigrant mothers were aware that "The Bureau of National Health Insurance provides children with fluoride varnish twice a year", indicating 


\begin{tabular}{|c|c|c|c|c|c|c|c|c|}
\hline \multirow[t]{2}{*}{ Characteristics } & \multicolumn{2}{|c|}{ Model F } & \multicolumn{2}{|c|}{ Model G } & \multicolumn{2}{|c|}{ Model H } & \multicolumn{2}{|c|}{ Model I } \\
\hline & $\mathrm{aOR}$ & $(95 \% \mathrm{Cl})$ & $\mathrm{aOR}$ & $(95 \% \mathrm{Cl})$ & aOR & $(95 \% \mathrm{Cl})$ & aOR & $(95 \% \mathrm{Cl})$ \\
\hline \multicolumn{9}{|l|}{ Race } \\
\hline Native & 1 & & 1 & & 1 & & 1 & \\
\hline Immigrant & 0.76 & $(0.37-1.59)$ & 1.12 & $(0.52-2.41)$ & 0.38 & $(0.17-0.83)$ & 0.73 & $(0.31-1.75)$ \\
\hline \multicolumn{9}{|l|}{ Age } \\
\hline$>=30$ & 1 & & 1 & & 1 & & 1 & \\
\hline$<30$ & 1.00 & $(0.58-1.74)$ & 0.60 & $(0.34-1.06)$ & 0.66 & $(0.36-1.23)$ & 0.81 & $(0.42-1.56)$ \\
\hline \multicolumn{9}{|l|}{ Educational level } \\
\hline College or higher & 1 & & 1 & & 1 & & 1 & \\
\hline High school & 0.85 & $(0.53-1.35)$ & 1.29 & $(0.76-2.16)$ & 0.55 & $(0.29-1.04)$ & 0.62 & $(0.32-1.20)$ \\
\hline Less than high school & 1.00 & $(0.44-2.28)$ & 1.13 & $(0.47-2.69)$ & 0.80 & $(0.30-2.13)$ & 0.10 & $(0.15-1.10)$ \\
\hline \multicolumn{9}{|l|}{ Household income } \\
\hline >NTD 59,999 & 1 & & 1 & & 1 & & 1 & \\
\hline NTD 40,000-59,999 & 1.26 & $(0.76-2.09)$ & 0.74 & $(0.42-1.28)$ & 0.64 & $(0.32-1.27)$ & 0.58 & $(0.29-1.12)$ \\
\hline$<$ NTD 40,000 & 0.88 & $(0.54-1.43)$ & 0.63 & $(0.37-1.07)$ & 0.81 & $(0.42-1.56)$ & 0.92 & $(0.46-1.84)$ \\
\hline Knowledge & 1.23 & $(1.08-1.40)$ & 1.05 & $(0.92-1.19)$ & 1.11 & $(0.97-1.28)$ & 0.97 & (0.84-1.13) \\
\hline Attitudes & 1.02 & $(0.99-1.04)$ & 1.04 & $(1.01-1.07)$ & 1.05 & $(1.02-1.08)$ & 1.03 & $(0.99-1.06)$ \\
\hline
\end{tabular}

aOR was adjusted for covariates in the table.

Model F: The first time mother assisted child in tooth brushing (before aged one year vs. after aged one year)

Model G: Replace child's toothbrush (Within three months vs. More than three months/broke).

Model H: Child regular dental check-up (Yes vs. No).

Model I: Visited a dentist in the past two years (Yes vs. No).

that mothers lack of health information regarding this protective service.

A greater level of knowledge and a more positive attitude toward oral hygiene are a prerequisite for successful caries preventive behaviors. Studies have reported that there is a link between the behavior of preschool children, such as brushing habits, and mothers' awareness, attitudes and behaviors $[9,10]$. In the present study, mothers who have higher level of caries-related knowledge were more likely to use of dental floss, fluoride toothpaste and dental visit in the past 2 years, as well as assist child in tooth brushing before the age of one. Our findings also showed that positive attitude toward oral health was associated with the oral hygiene behavior. Mothers who have positive attitudes toward oral health were more likely to replace child's toothbrush within three months and take their child regular dental check-ups.

A positive relationship was found between preventive health care for children and the SES of their families [24]. Dental caries can be prevented by professionally applied topical fluorides, dental sealants, and the use of fluoride toothpastes. However, children from low income families were found to have worse oral health outcomes, fewer dental visits, and fewer protective sealants [25]. Immigrant mothers are often limited by their language barriers and low SES, resulting in a lower utilization rate of preventive health care and services. In addition, a lack of message readiness may explain the lower access to dental visits. Studies have reported that a link exists between access to health information and socioeconomic status $[26,27]$. In this study, immigrant families showed evidence of a low economic and living standard; more than half were living in households with the lowest household income and parental education levels. Exposure to media messages has increased in Taiwanese society, but health information is still not readily available for lower socioeconomic segments of the population.

The data in our study was collected from self-reported questionnaires. Mothers may not have presented the actual situation due to social desirability considerations. Nevertheless, the questionnaires were anonymously recorded; consequently, the validity doubts regarding answer errors should have been avoided. The data obtained in this study may not be generalizable to all communities within our county. However, the study methodology and research network might be extended to areas where Southeast Asian immigrant women in arranged transnational marriages are common.

\section{Conclusions}

Immigrant-native differences regarding caries-related knowledge, attitudes, and behaviors were identified. A lower 
level of knowledge, negative attitudes toward oral hygiene, and the frequency of oral health behavior in immigrant mothers may affect the oral health of their children. A lack of message readiness among these immigrant mothers with a language barrier may explain the lower access to dental visits. The findings suggested a need of designing effective health communication in cross-cultural caries prevention programs for these immigrant minorities to raise risk awareness and dental services aimed at reducing immigrant-native disparities in child oral health care.

\section{Competing interests}

The authors declare that they have no competing interests.

\section{Authors' contributions}

CCC is the primary writer of the manuscript and participated in the study implementing. SJC and CCT conceived of the study, and had made substantial contributions to conception and design, and revised the manuscript critically for important intellectual content. YCL, CCH and FLC participated in the design of the study, acquisition of data, and revised the manuscript. CHL assisted in statistical analysis, interpretation of data and draft the statistical analysis of manuscript. TC, CSC and YYL revised the manuscript critically for important intellectual content. HLH is the principal investigator of this project. She contributed to the design, sampling protocol and method development, statistical analysis and interpretation of the results, and has been involved in drafting and revising the manuscript. All authors read and approved the final manuscript.

\section{Acknowledgments}

This work was supported by the National Science Council of Taiwan [grant numbers NSC 99-2314-B-037-036-MY2; NSC 101-2314-B-037-039-MY3].

\begin{abstract}
Author details
${ }^{1}$ Department of Oral Hygiene, College of Dental Medicine, Kaohsiung Medical University, 100 Shih-Chuan 1st Road, Kaohsiung 80708, Taiwan. ${ }^{2}$ Institute of Occupational Safety and Health, Council of Labor Affairs, Executive Yuan, New Taipei City, Taiwan. ${ }^{3}$ Department of Health Care Management, College of Healthcare Administration and Management, National Taipei University of Nursing and Health Sciences, Taipei, Taiwan. ${ }^{4}$ School of Dentistry, College of Dental Medicine, Kaohsiung Medical University, Kaohsiung, Taiwan. ${ }^{5}$ Institute of Population Health Sciences, National Health Research Institutes, Miaoli County 350, Taiwan. ${ }^{6}$ Department of Public Health, College of Medicine, Fu Jen Catholic University, New Taipei City, Taiwan. 'Department of Public Health, College of Health Science, Kaohsiung Medical University, Kaohsiung, Taiwan. ${ }^{8}$ Department of Global Community Health and Behavioral Sciences, School of Public Health and Tropical Medicine, Tulane University, 70112 New Orleans, LA, USA. ${ }^{9} \mathrm{Global}$ Center of Excellence for Oral Health Research and Development, Kaohsiung Medical University, Kaohsiung, Taiwan. ${ }^{10}$ Department of Nursing, Shu-Zen College of Medicine and Management, Kaohsiung, Taiwan.
\end{abstract}

Received: 13 August 2013 Accepted: 7 January 2014

Published: 14 January 2014

\section{References}

1. Sheiham A: Dental caries affects body weight, growth and quality of life in pre-school children. Br Dent J 2006, 201(10):625-626.

2. Kranz $\mathrm{S}$, et al: Adverse effect of high added sugar consumption on dietary intake in American preschoolers. J Pediatr 2005, 146(1):105-111.

3. Hobdell M, et al: Global goals for oral health 2020. Int Dent J 2003, 53(5):285-288

4. MOI Ministry of the Interior: Taiwan area the number of marriages by nationality of bride and groom. Republic of China: Taipei: Ministry of the Interior; 2012.

5. Tapias-Ledesma MA, et al: Use of dental care and prevalence of caries among immigrant and Spanish-born children. J Dent Child 2011, 78(1):36-42.

6. Maserejian NN, et al: Oral health disparities in children of immigrants: dental caries experience at enrollment and during follow-up in the New England Children's Amalgam Trial. J Public Health Dent 2008, 68(1):14-21.
7. Werneck Rl, et al: Early childhood caries and access to dental care among children of Portuguese-speaking immigrants in the city of Toronto. J Can Dent Assoc 2008, 74(9):805.

8. Lin YC, et al: Oral health disparities of children among southeast Asian immigrant women in arranged transnational marriages in Taiwan. Caries Res. in press.

9. Skeie MS, et al: Parental risk attitudes and caries-related behaviours among immigrant and western native children in Oslo. Community Dent Oral Epidemiol 2006, 34(2):103-113.

10. Finlayson TL, et al: Maternal self-efficacy and 1-5-year-old children's brushing habits. Community Dent Oral Epidemiol 2007, 35(4):272-281.

11. Yang YM, Wang HH: Life and health concerns of Indonesian women in transnational marriages in Taiwan. J Nurs Res 2003, 11(3):167-176.

12. Buss PM: Globalization and disease: in an unequal world, unequal health! Cad Saude Publica 2002, 18(6):1783-1788.

13. ILO World Commission on the Social Dimension of Globalization: A fair globalization: Creating opportunities for all. Geneva: International Labour Organization (ILO); 2004.

14. Lin SL, Hsiao YL: Social segregation and the health care of female immigrants in Taiwan [Article in Chinese]. J Nurs 2007, 54(4):67-72.

15. Manski RJ, Cooper PF: Dental care use: does dental insurance truly make a difference in the US? Community Dent Health 2007, 24(4):205-212.

16. Zuvekas SH, Weinick RM: Changes in access to care, 1977-1996: the role of health insurance. Health Serv Res 1999, 34(1 Pt 2):271-279.

17. Tsai WC, Kung PT, Chang WC: Influences of market competition on dental care utilization under the global budget payment system. Community Dent Oral Epidemiol 2007, 35(6):459-464.

18. Plescia M, Groblewski M, Chavis L: A lay health advisor program to promote community capacity and change among change agents. Health Promot Pract 2008, 9(4):434-439.

19. Schulz AJ, et al: The east side village health worker partnership: integrating research with action to reduce health disparities. Public Health Report 2001, 116(6):548-557.

20. Glanz K, Rimer BK, Viswanath K: Health behavior and health education: theory, research, and practice. 4th edition. San Francisco: Jossey-Bass Inc; 2008.

21. Ajzen I: The theory of planned behavior. Org Behav and human Decis Processes 1991, 50(2):179-211.

22. Sundby A, Petersen PE: Oral health status in relation to ethnicity of children in the municipality of Copenhagen, Denmark. Int J Paediatr Dent 2003, 13(3):150-157.

23. Pine $\mathrm{CM}$, et al: International comparisons of health inequalities in childhood dental caries. Community Dent Health 2004, 21(1 Suppl):121-130.

24. Ebersole $\mathrm{L} \mathrm{L}$, et al: Oral health disparities and the future face of America. J Dent Res 2012, 91:997-1002.

25. Mouradian WE, Wehr E, Crall JJ: Disparities in children's oral health and access to dental care. JAMA 2000, 284(20):2625-2631.

26. Dutta-Bergman MJ: Reaching unhealthy eaters: applying a strategic approach to media vehicle choice. Health Commun 2004, 16(4):493-506.

27. Gillespie A, Robins K: Geographic inequalities: the spatial bias of the new communication technologies. J Commun 1989, 39(3):7-18.

doi:10.1186/1472-6831-14-3

Cite this article as: Chen et al:: Immigrant-native differences in cariesrelated knowledge, attitude, and oral health behaviors: a cross-sectional study in Taiwan. BMC Oral Health 2014 14:3.

\section{Submit your next manuscript to BioMed Central and take full advantage of:}

- Convenient online submission

- Thorough peer review

- No space constraints or color figure charges

- Immediate publication on acceptance

- Inclusion in PubMed, CAS, Scopus and Google Scholar

- Research which is freely available for redistribution 